\title{
Photoelectric fields in doped lithium niobate crystals
}

\author{
N. V. Sidorov ${ }^{a}$, A. M. Shuvalova ${ }^{a}$, A. A. Yanicheva ${ }^{a}$ N. A. Teplyakova ${ }^{a}$, \\ M. N. Palatnikov ${ }^{\mathrm{a}}$, and K. Bormanis ${ }^{\mathrm{b}}$ \\ ${ }^{a}$ Tananaev Institute of Chemistry - Subdivision of the Federal Research Centre "Kola Science Centre of \\ the Russian Academy of Sciences", Science Centre of Russian Academy of Sciences, Apatity, Russia; \\ Institute of Solid State Physics, University of Latvia, Riga, Latvia
}

\begin{abstract}
Photoinduced light scattering (PILS) in nominally pure stoichiometric and congruent lithium niobate single crystals $\left(\mathrm{LiNbO}_{3}\right)$, and ones doped with $\mathrm{B}^{3+}, \mathrm{Cu}^{2+}, \mathrm{Zn}^{2+}, \mathrm{Mg}^{2+}, \mathrm{Gd}^{3+}, \mathrm{Y}^{3+}, \mathrm{Er}^{3+}$ cations was studied. All crystals have a relatively low effect of photorefraction and are promising materials for frequency conversion, electro-optical modulators and shutters. It was found that the photovoltaic and diffusion fields for some crystals have a maximum at a wavelength of $514.5 \mathrm{~nm}$. All the crystals studied are characterized by a maximum of the integral intensity of the speckle structure of the PILS at a wavelength of $514.5 \mathrm{~nm}$.
\end{abstract}

\section{ARTICLE HISTORY}

Received 2 October 2018

Accepted 8 February 2019

\section{KEYWORDS}

Single crystal of lithium niobate; photorefractive effect; Rayleigh photoinduced light scattering; photovoltaic and diffusion fields

\section{Introduction}

The ferroelectric photorefractive lithium niobate crystal $\left(\mathrm{LiNbO}_{3}\right)$ is characterized by a high value of spontaneous polarization, large values of the photoinduced electric fields intensity $[1,2]$. The control of the photorefraction (optical damage) magnitude is usually carried out by doping of the crystal with cations of various metals [1, 2]. Photorefractive effect causes Rayleigh photoinduced light scattering, which occurs on static and dynamic (fluctuating) defects with an altered refractive index induced by laser radiation $[3,4]$. In this case, the value of the electro-optical effect determines the value of the angle $\theta$ of the PILS indicatrix opening in the crystal [4].

In this paper, the angular distribution of the intensity of the speckle structure of the PILS as a function of the wavelength of the exciting laser radiation was studied. Experiments were performed in nominally pure stoichiometric $\left(\mathrm{LiNbO}_{3 \text { stoich }}\right)$ and congruent $\left(\mathrm{LiNbO}_{3 \text { cong }}\right)$ lithium niobate single crystals, and ones doped with $\mathrm{B}^{3+}, \mathrm{Cu}^{2+}, \mathrm{Zn}^{2+}$, $\mathrm{Mg}^{2+}, \mathrm{Gd}^{3+}, \mathrm{Y}^{3+}, \mathrm{Er}^{3+}$ cations. The following laser lines were used in PILS experiment: 476.5, 488.0, 514.5 and $532.0 \mathrm{~nm}$. Quantitative estimation of the photovoltaic $\left(E_{p v}\right)$ and diffusion $\left(E_{D}\right)$ fields values were made using the approach described in [3].

\section{Experiment setup}

$\mathrm{LiNbO}_{3}$ crystals were grown from the congruent melt at the "Crystal-2" installation by the Czochralski technique in air [5]. $\mathrm{LiNbO}_{3 \text { stoich }}$ crystal was grown from the melt with 
$58.6 \mathrm{~mol}$. \% of $\mathrm{Li}_{2} \mathrm{O}$. PILS registration was carried out using an installation, described in details in [4]. For the PILS registration the following lines of Spectra Physics (2018-RM) argon-krypton laser were used: $476.5 \mathrm{~nm}(P=216 \mathrm{~mW}), 488.0 \mathrm{~nm} \quad(P=98 \mathrm{~mW})$, $514.5 \mathrm{~nm}(P=282 \mathrm{~mW})$ and $532.0 \mathrm{~nm}(P=160 \mathrm{~mW})$. The value of the intensity of the photovoltaic and diffusion fields in crystals was calculated in the Mathcad 15.0 program using the approach proposed in [3]. The refractive indices of the extraordinary and ordinary rays were determined from empirical equations [6].

\section{Results and discussion}

The speckle structure of the PILS pattern of $\mathrm{LiNbO}_{3}$ crystals is determined by the features of the secondary structure of the crystal, which depends significantly on the composition and growing technology $[1,2,4]$. The birefringence of the crystal, both intrinsic and induced by laser radiation, is also important. At a power of excitation laser radiation of $160 \mathrm{~mW}$, the indicatrix of the speckle structure of the PILS in $\mathrm{LiNbO}_{3}$, $\mathrm{LiNbO}_{3}: \mathrm{Zn}$ (2.93), $\mathrm{LiNbO}_{3}: \mathrm{Gd}$ (0.002): $\mathrm{Mg}$ (0.04), $\mathrm{LiNbO}_{3}$ : $\mathrm{Er}$ (3.1 wt. \%) crystals is not revealed, and only circular scattering on crystal lattice defects is observed. For all other crystals investigated the indicatrix of the PILS is asymmetric with the form of a figure eight or an ellipse stretched along the polar axis.

It should be noted that for the $\mathrm{LiNbO}_{3}$ : Y (0.46wt. \%) crystal at $P=160 \mathrm{~mW}$, the indicatrix of the speckle structure of the PILS is revealed very rapidly, in a time of about $1 \mathrm{~s}$. For all other crystals, the opening time of the speckle structure of the PILS is about $60 \mathrm{~s}$.
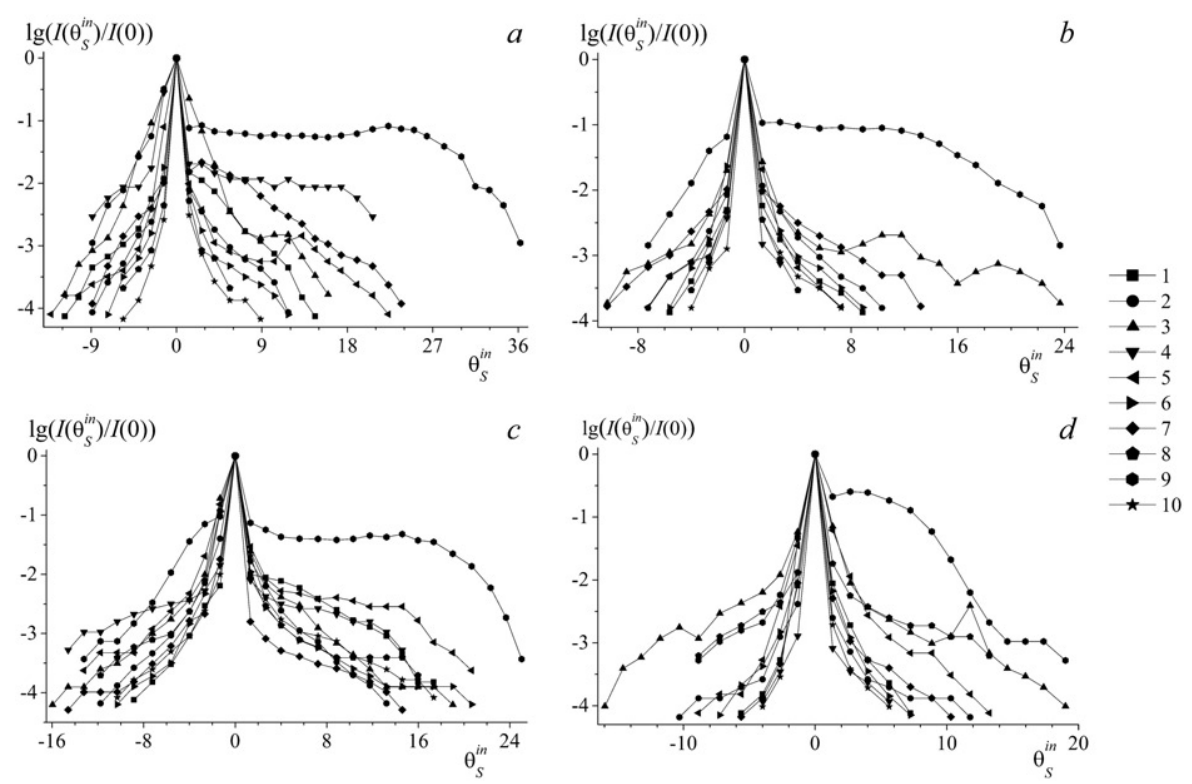

Figure 1. The angular distribution of the scattered light intensity at $\lambda=476.5(a), 488.0(b), 514.5(c)$, 532 (d) $\mathrm{nm}$ for the following crystals: $\mathrm{LiNbO}_{3}: \mathrm{Zn}(0.018)(1)$; $\mathrm{LiNbO}_{3}: \mathrm{Zn}(2.93)(2) ; \mathrm{LiNbO}_{3}: \mathrm{Y}(0.46)$ (3); $\mathrm{LiNbO}_{3}: \mathrm{Cu}(0.007): \mathrm{Gd}(0.02)$ (4); $\mathrm{LiNbO}_{3}: \mathrm{Gd}(0.05)$ (5); $\mathrm{LiNbO}_{3}: \mathrm{Gd}(0.002): \mathrm{Mg}(0.4)$ (6); $\mathrm{LiNbO}_{3}: \mathrm{B}(0.08$ in the reacted mixture) (7); $\mathrm{LiNbO}_{3}: \operatorname{Er}\left(3.1 \mathrm{wt}\right.$ \%) (8); $\mathrm{LiNbO}_{3 \text { stoich }}$ (9); $\mathrm{LiNbO}_{3 \text { cong }}(10)$. 

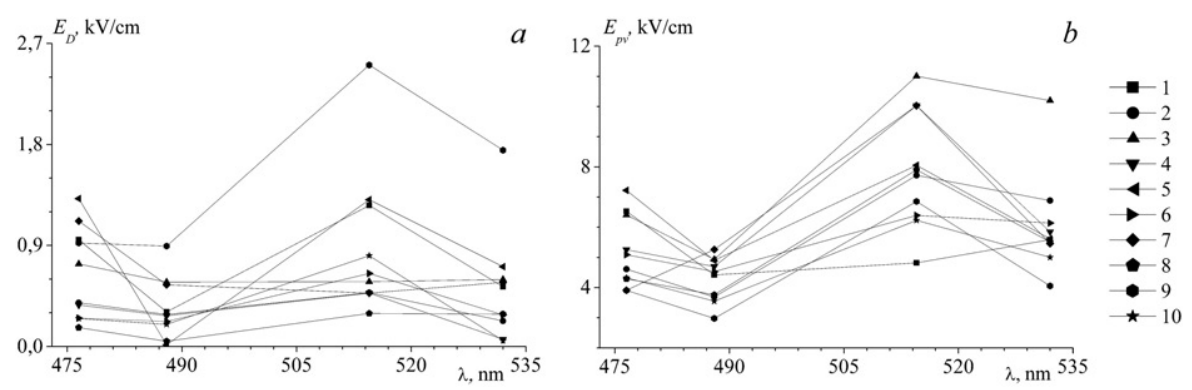

Figure 2. Dependence of $E_{D}(a)$ and $E_{p v}(b)$ on laser line wavelength for $\mathrm{LiNbO}_{3}$ crystals with various composition: $\mathrm{LiNbO}_{3}: \mathrm{Zn}$ (0.018) (1); $\mathrm{LiNbO}_{3}: \mathrm{Zn}$ (2.93) (2); $\mathrm{LiNbO}_{3}: \mathrm{Y}(0.46)$ (3); $\mathrm{LiNbO}_{3}: \mathrm{Cu}$ (0.007):Gd (0.02) (4); $\mathrm{LiNbO}_{3}: \mathrm{Gd}(0.05)(5) ; \mathrm{LiNbO}_{3}: \mathrm{Gd}(0.002): \mathrm{Mg}(0.4)(6) ; \mathrm{LiNbO}_{3}: \mathrm{B}$ (0.08 in the reacted mixture) (7); $\mathrm{LiNbO}_{3}: \mathrm{Er}$ (3.1 wt. \%) (8); $\mathrm{LiNbO}_{3 \text { stoich }}$ (9); $\mathrm{LiNbO}_{3 \text { cong }}(10)$.

It can be seen from Figure 1 that crystals $\mathrm{LiNbO}_{3 \text { stoich, }} \mathrm{LiNbO}_{3}$ : $\mathrm{Gd}(0.05)$ and $\mathrm{LiNbO}_{3}: \mathrm{Y}(0.46 \mathrm{wt} . \%)$ possess the greatest asymmetry and the scattered radiation angle $\theta$ in the series of crystals studied, regardless of the wavelength of the exciting line. At the same time, for a $\mathrm{LiNbO}_{3 \text { stoich }}$ crystal, the shape of the scattering curve when excited by laser lines $476.5,488.0$, and $532.0 \mathrm{~nm}$ is approximately the same, but differs significantly from them when excited by a $514.5 \mathrm{~nm}$ laser line, Figure 1.

Figure 2 shows the dependences of the $E_{p v}$ and $E_{D}$ intensities in the investigated crystals on the wavelength of the exciting radiation. For $\mathrm{LiNbO}_{3}: \mathrm{Zn}(0.018), \mathrm{LiNbO}_{3}: \mathrm{Zn}$ (2.93), $\mathrm{LiNbO}_{3}: \mathrm{Gd}\left(0.05\right.$ wt. \%) crystals, a maximum in the $E_{D}$ dependence at the length of the exciting laser line of $514.5 \mathrm{~nm}$ is observed. However, the maximum in the $E_{D}$ dependence are not observed for $\mathrm{LiNbO}_{3}: \mathrm{Er}(3.1), \mathrm{LiNbO}_{3}$ : B (0.08), $\mathrm{LiNbO}_{3}$ : Y (0.46 wt. \%) crystals.

For $\mathrm{LiNbO}_{3}: \mathrm{Y}$ (0.46), $\mathrm{LiNbO}_{3}: \mathrm{Cu}(0.007)$ : $\mathrm{Gd}(0.02), \mathrm{LiNbO}_{3}$ : B (0.08 wt. \%), $\mathrm{LiNbO}_{3}: \mathrm{Gd}(0.05), \mathrm{LiNbO}_{3}: \mathrm{Zn}\left(2.93 \mathrm{wt}\right.$ \%), $\mathrm{LiNbO}_{3 \text { stoich }}$ crystals the maximum in the $E_{p v}$ dependence is also observed at the length of the exciting laser line of $514.5 \mathrm{~nm}$. But at the same time, the maximum is absent for $\mathrm{LiNbO}_{3}: \mathrm{Zn}(0.018), \mathrm{LiNbO}_{3}$ : Gd (0.02): $\mathrm{Mg}(0.4)$ crystals. It is also seen from Figure 2 that the $\mathrm{LiNbO}_{3 \text { stoich }}$ crystal at wavelengths of the exciting radiation of $476.5,488.0$ and $532.0 \mathrm{~nm}$ and $\mathrm{LiNbO}_{3}: \mathrm{Zn}$ (0.018 wt. \%) at $514.5 \mathrm{~nm}$ possess the smallest value of the $E_{p v}$.

\section{Summary}

Photoinduced light scattering in nominally pure $\mathrm{LiNbO}_{3 \text { stoich }}$ and $\mathrm{LiNbO}_{3 \text { cong }}$ single crystals $\left(\mathrm{LiNbO}_{3}\right)$, and ones doped with $\mathrm{B}^{3+}, \mathrm{Cu}^{2+}, \mathrm{Zn}^{2+}, \mathrm{Mg}^{2+}, \mathrm{Gd}^{3+}, \mathrm{Y}^{3+}, \mathrm{Er}^{3+}$ cations was studied. According to the characteristics of the PILS, a quantitative estimation of the intensity of the photovoltaic and diffusion fields was made. It was found that the $E_{p v}$ and $E_{D}$ for some crystals have a maximum at a wavelength of $514.5 \mathrm{~nm}$. However, for the $\mathrm{LiNbO}_{3}$ : Y crystal $\left(0.46 \mathrm{wt}\right.$. \%) there is no maximum in the $E_{p v}$ dependence, but one at a wavelength of $514.5 \mathrm{~nm}$ in $E_{D}$ dependence.

\section{References}

1. N. V. Sidorov, T. R. Volk, B. N. Mavrin, and V. T. Kalinnikov, Lithium Niobate: Defects, Photorefraction, Vibrational Spectrum and Polaritons (Nauka, Moscow, Russia 2003). 
2. T. Volk, and M. Wohlecke, Lithium Niobate: Defects, Photorefraction and Ferroelectric Switching (Springer, Berlin, Germany 2008).

3. M. Goulkov, M. Imlau, and T. Woike, Photorefractive parameters of lithium niobate crystals from photoinduced light scattering, Phys. Rev. B. 77, 235110-1 (2008).

4. V. A. Maksimenko, A. V. Syuy, and Y. M. Karpets, Photoindeced Processes in Lithium Niobate Crystals (Physmatlit, Moscow, Russia 2008).

5. M. N. Palatnikov et al., Growth and concentration dependencies of rare-earth doped lithium niobate single crystals, J. Cryst. Growth. 291(2), 390 (2006). DOI: 10.1016/ j.jcrysgro.2006.03.022.

6. G. G. Gurzadyan, V. G. Dmitriev, and D. N. Nikogosyan, Nonlinear Optical Crystals: Properties and Applications in Quantum Electronics (Radio and Communication, Moscow, Russia 1991). 